Periodica Polytechnica
Social and Management Sciences

23(2), pp. 133-141, 2015

DOI: $10.3311 /$ PPso. 7763

Creative Commons Attribution (1)

RESEARCH ARTICLE

\section{Social Capital: A Comprehensive Overview at Organizational Context}

\author{
Elias Milana $^{1 *}$, Issa Maldaon ${ }^{1}$
}

Received 16 October 2014; accepted after revision 05 February 2015

\begin{abstract}
A large number of authors, researchers and organizational theorists have invoked the concept of social capital in the search for description of the role of human resource in organization. Social capital reflects extent of social relationships which contribute to the achievement of organization's goals, through social networks, norms, obligations and other patterns arising from social interactions. This study intends to clarify the concept and helps to evaluate its utility for organizational theory. The purpose of the paper is to identify the importance of social capital as a factor in achieving sustainable growth and development, and to identify its role in the organization. This study emphasizes the essential role of social capital in organizations, the importance of its development, and the possibilities of making it compatible with the goals of the organization.
\end{abstract}

\section{Keywords}

social capital, social networks, norms and shared belief, social interactions

\footnotetext{
${ }^{1}$ Department of Business Administration, Economics Faculty,

Damascus University, Syrian Arab Republic

*Corresponding author, e-mail: milanabaik@gmail.com
}

\section{Introduction}

Over the past several years, many organizations have focused on reigning in key financial indicators. By searching the global labor market for the most efficient resources, creating process improvements, and using technology to speed up operations, companies have improved financial performance and created competitive advantages. But downsizing, outsourcing, and offshoring will soon reach upper limits on their ability to improve organizational performance. In addition, these actions are available to all competitors - making them, at best, temporary sources of competitive advantage. Thus, the source of which will lead to improved performance, and is continuing source (not temporary) is the satisfaction factor associated with organizational performance. In today's work environment, few objectives are met solely through one individual's efforts. In addition, as people work together in group settings, they are likely to influence each other's attitudes and beliefs. Because of the roles that teamwork and joint effort play in organizational success today, tapping into these elements seems critical (Leimbach, 2006).

New managerial paradigm insists that employees should be treated and considered primarily as human brains that have their own wants, needs, personal desires (Aziri, 2011).

Human resources should be considered the most important asset of an organization, because it would have a key role in achieving an organization's goals. The main element of growth and development is manpower in each organization. Organizations could not affect the environment and wouldn't be successful in competition arenas, even if they had the best technologies or facilities, but they didn't have skilled and efficient manpower. High quality of human resource means higher probability of organizational success and survival (Savari et al., 2013).

Interpersonal relations can affect individual attitudes and behavior. Social relations established in the work environment can provide individuals with benefits, which affect their level of job satisfaction. They intentionally build social ties so as to have access to resources of others or, alternatively, take advantage of being embedded in social networks (Zappa and Zavarrone, 2009). When trust and social networks flourish, individuals, firms, neighborhoods, and even nations prosper (Putnam, 2000). 
Indicated Zappa, Zavarrone (2009) that social interaction can affect job satisfaction directly intervening on its formation. satisfaction results from a collective evaluation process, which involves either the individual or his surrounding environment, This mechanism, named social contagion, implies one's attitudes and perceptions depend on the social context in which they are formulated, and from which one experiences the pressure to conform. Hence, interpersonal relations contribute to develop attitudes, since the individuals see the opinions of their significant alters they are somehow connected to as an appropriate benchmark against which to compare their own opinion and further include alters evaluations into their own evaluations.

Alters influence on individuals perceptions can be either intentional or un-intentional and be exerted through communication when individuals directly interact and exchange their opinion on a specific topic or comparison, when one tends to behave like others who occupy a similar position in the network of relationships and, being subject to analogous opportunities and constraints, develops similar perceptions.

Leana and Van Buren (1999) propose that organizationbased high social capital improves organizational performance because it leads employees to be more committed to the organization, more to willing to work flexibly, more likely to subordinate their own goals to the organization's needs, and more interested in investing in the specialized skills and knowledge organization's needs. Higher level of social capital would result in organizational performance. Add Savari et al. (2013) that employees with higher levels of loyalty and commitments are considered one of the indicators representing success of some organizations than others. This fact increases the performance, efficiency and effectiveness of the organizations.

Quality of social relations among members is seen as a key to unlocking assets in their organization. The strength of social capital is that it can incorporate the organization's objectives at the same time as it highlights the social relations which are important for the psychological work environment and thus can be of critical importance to an employee's job satisfaction and commitment (Rostami et al., 2013). A large social network could lead to higher individual performance because the worker has much contacts with whom can draw advice and support in gifting things done (Ariani, 2012).

Interactions amongst social actors create a complex web of social networks that make possible the exchange of information and the acquisition of skills. Furthermore, with a more significant social capital, some companies get an advantage over the others. The people and organizations with better performances are better in accessing and taking advantage of the resources and opportunities that their contacts and relationships make available (Oliveira, 2013). From the above, we will like to answer the following questions in our study:

- What is social capital, and what are the sources that generate it?
- What nature of contribution of social capital to achieve appropriate performance?

\section{Concept of social capital}

Nahapiet and Ghoshal (1998) proposed that organizations' ability to foster social capital by bringing people together for recurrent interaction over time provides organizations with a performance advantage.

Indicated Karahanna and Preston (2013) that the social capital literature further argues that differences in organizational performance may represent differences in the ability of organizations to create and exploit social capital. According to Adler and Kwon (2002) the core intuition guiding social capital research is that the goodwill that others have toward each other is a valuable resource. By goodwill we refer to the sympathy, trust, and forgiveness offered us by friends and acquaintances. If goodwill is the substance of social capital, its effects flow from the information, influence, and solidarity such goodwill makes available. Social capital is source lies in the structure and content of the actor's social relations.

In same context, indicated Helliwell (2001) that high levels of interpersonal trust, to the extent that this trust is matched by trustworthy behavior in others, do make many aspects of life more enjoyable and more productive.

Indicated Chazon (2009) that social interactions that form strong relational bonds and that result in high levels of trust and cooperation are a valuable resource.

Indicated Baker (1990) that social capital is a resource that actors derive from specific social structures and then use to pursue their interests. Burt (1992) see that social capital is friends, colleagues, and more general contacts through whom actor receive opportunities to use his financial and human capital. Indicated Portes (1998) that social capital is the ability of actors to secure benefits by virtue of membership in social networks or other social structures. And he Distinguish three basic functions of social capital: (a) as a source of social control, (b) as a source of family support, (c) as a source of benefits through extra-familial networks. Portes and Sensenbrenner (1993) think than social capital is expectations for action within a collectivity that affect the economic goals and goal-seeking behavior of its members, even if these expectations are not oriented toward the economic sphere. Social capital facilitates knowledge integration by reducing the perception of organizational actors that other group members would potentially act opportunistically and helps to develop shared goals among different stakeholders (Karahanna and Preston, 2013).Social capital refers to features of social organization such as networks, norms, and social trust that facilitate coordination and cooperation for mutual benefit (Putnam, 1995). Nahapiet and Ghoshal defined social capital as the sum of the actual and potential resources embedded within, available through, and derived from the network of relationships possessed by an individual or 
social unit. Social capital thus comprises both the network and the assets that may be mobilized through that network.

Putnam (2000) argued that the core idea of social capital is that social networks have value, Social contacts affect the productivity of individuals and groups.

Indicated (Schaik, 2002) that basic to the notion of social capital is that people spend their resources on others, that people invest in each other and that people can mobilize the resources of others. Not only of significant others that are near and dear, but also of more distant and generalized others

According to Coleman (2012) social capital is defined by its function. It is not a single entity, but a variety of different entities, with two elements in common: they all consist in some aspect of social structure, and they facilitate certain actions of actors within the structure. Indicate Flap and Volker (2001) that within the theory of social capital, personal networks are considered to be a means to achieve individual goals. In same context, argued Fu (2004) that the actions of individuals and groups can be greatly facilitated by membership in specific social networks, specifically by their direct and indirect links to other actors in those networks. Tian et al. (2011) see that strong ties within the firm and to other strategically related firms enjoy better access to more and higher quality information, which results in superior advice to the firm and better financial outcomes. Social capital is critical for collective work and effective interpersonal coordination, it makes collective work easier and facilitates economic and community development. Social capital is an important source because individuals work together more effectively and efficiently when they know one another, understand one another, and trust and identify with one another (Ariani, 2012).

Indicated Oliveira (2013) that network relationships are a corporate skill that is extremely hard to copy because they are complex, idiosyncratic, and socially built.

Argue Karahanna and Preston (2013) that organizational advantage can be derived from the collective ability of organizational actors to exchange, combine, and integrate knowledge and that social capital enables and facilitates such knowledge exchange and combination. Add Fu (2004) that social capital inheres in personal connections and interpersonal interactions, together with the shared sets of values that are associated with these contacts and relationships. The major composition of network is size (the number of ties that a person has in his personal network) and heterogeneity (the tendency toward similar or diverse actors within a network). The structure of a network refers to the relative density of links among people within it that facilitate the flow of information and the provision of social support to the social structure in which a person or a tie is embedded.

Oliveira (2013) list four important factors to obtain new knowledge from a relationship network: a) there must be some opportunity to combine and exchange skills (accessibility to social knowledge). b) all parts must be open to the possibility of exchanging knowledge, and confident that it will be possible to develop new skills. c) all parts must be motivated to develop some knowledge, even though they don't know if it will actually happen, and even though they don't know the value of that knowledge; d) it's vital that the parts be capable not only of recognizing the value of new knowledge and information, but also of absorbing it and putting it into practice. In that, Portes (1998) indicated that the social interactions differ from purely that economic exchange in two aspects. First, the currency with which obligations are repaid may be different from that with which they were incurred in the first place and may be as intangible as the granting of approval or allegiance. Second, the timing of the repayment is unspecified. Lin (1999) showed three explanations can be offered as to why embedded resources in social networks will enhance the outcomes of actions: First, it facilitates the flow of information. Second, these social ties may exert influence on the agents who play a critical role in decisions involving the actor. Some social ties, due to their strategic locations and positions carry more valued resources and exercise greater power in organizational agents' decision making. Third, social resources, and their acknowledged relationships to the individual, may be conceived by the organization or its agents as certifications of the individual's social credentials, some of which reflect the individual's accessibility to resources through social networks and relations.

Bourdieu (1986) has argued that capital exists in three fundamental forms: Economic capital that can be directly convertible into money and institutionalized in the form of property rights, Cultural capital that may be convertible into economic capital and institutionalized in the form of educational qualification. cultural capital exists in various forms, it includes longstanding dispositions and habits acquired in the socialization process, the accumulation of valued cultural objects such as formal educational qualifications and training. And social capital, made up of social obligation that can be convertible into economic capital and institutionalized in the form of a title of nobility. Anheier et al. (1995) distinction between incorporated cultural capital, in the form of education and knowledge, and symbolic cultural capital, the capacity to define and legitimize cultural, moral and artistic values, standards, and styles. Add Anheier et al. (1995) that social capital is the sum of the actual and potential resources that can be mobilized through membership in social networks of actors and organizations. In the same context, indicated Portes (1998) that whereas economic capital is in people's bank accounts and human capital is inside their heads, social capital inheres in the structure of their relationships. To possess social capital, a person must be related to others, and it is these others, not himself, who are the actual source of his or her advantage.

In the similar context, Edwards (2004) distinction between four types of capital:

- Produced economic capital: the produced means of production like machinery, equipment and structures, but 
also non-production related infrastructures, non- tangible assets, and the financial assets that provide command over current and future output streams.

- Natural capital: the renewable and non-renewable resources which enter the production process and satisfy consumption needs, as well as environmental assets that have amenity and productive use, and are essential for the life support system.

- Human capital: the knowledge, skills, competencies and attributes embodied in individuals that facilitate the creation of personal wellbeing.

- Social capital: Networks, together with shared norms, values and understanding that facilitate co-operation within and between groups.

Nahapiet and Ghoshal (1998) distinction between three dimensions of social capital:

- First, the relational dimension of social capital describes the kind of personal relationships people have developed with each other through a history of interactions. This concept focuses on the particular relations people have, such as respect and friendship, that influence their behavior.

In same context, Tomlinson (2011) add that the relational dimension explores the nature of linkages and the degree to which actors are embedded in such networks. This facet embodies business liaisons, particularly behavior, trust, and attitudes that exist between firms within the network. Also, indicated Ariani (2012) that the relational dimension refers to the kind of personal relationship that people have developed with each other through a history of interactions. This dimension is characterized by high level of trust, shared norms, obligation, and identification. Further, using the perspective of social capital theory, the relational dimension is based more on social resources theory that focuses on the characteristics of a relation, It can be concluded that relational dimension illustrate the types and characteristics of personal relations based on trust, which is in accordance with the social exchange theory. The theory states that individuals are willing to be useful for others in the exchange process.

Trust is a key mechanism by which the relational social capital effects are achieved. Trust enables individuals to be more open to exchanges of intellectual capital and anticipate more value through these exchanges. The potential value of relationships cannot be fully realized if relational members do not trust one another and are thereby not fully willing to share knowledge, even when these members readily have access to one another (Karahanna and Preston, 2013).

Add Oliveira (2013) that in the relational dimension of social capital the focus becomes the content and the characteristics of the relationships. It refers to each one of the individual relationships among one actor and all the others, concerning its intensity, multiplicity- meaning how many roles an actor plays in that relationship- and implicit rules. Also, frequency of interactions amongst actors, that is very important to tighten their relationships... Where, individuals that show more trust and that are seen as more trustable are more likely to use their relationships in their favor.

- Second, Structural dimension concerns the properties of the social system and of the network of relations as a whole. The term describes the impersonal configuration of linkages between people or units. Its refer to the overall pattern of connection between actors. In same context, Tomlinson (2011) indicated that the structural dimension relates to the loci of actors within a network, the network structure and the degree to which it encourages social interaction between actors. Indicated Karahanna, Preston (2013) that the structural dimension of social capital influences knowledge integration by enabling access to parties for exchanging knowledge and participating in knowing activities. Added Oliveira (2013) that the argument of the social capital's structural dimension is that quantity of and diversity in the relationships are key features in defining the access to more resources, which, in turn, can be used to achieve better performances.

- Third dimension of social capital is cognitive dimension, refers to those resources providing shared representation, interpretations, and systems of meaning among parties. In other word, the cognitive dimension refers to the collective goals or shared vision that emerge between actors within the network. Indicated Ariani (2012) that cognitive dimension which is attached to shared regulations and paradigm. The cognitive dimension or intellectual capital refers to shared language and codes and the ability to share knowledge. This dimension helps create general understanding on the shared goals and right ways to act in the social system. This dimension points out individual skills in judging and interpreting his work relation with his colleagues or supervisors. Using social capital theory, this dimension is based on the social resources theory that focuses on relational characteristics. The cognitive dimension also shows accessibility, distribution, interpretation, and denotation. Workers want to do something which is not their obligation if they understand each other.

Oliveira (2013) point out two important features of this dimension: the objectives, and the culture that the network members share. When the objectives and strategies of a network are clearly outlined and known by all the members, there will be a common comprehension of what is intended and what the available means that can be used in order to reach those goals. The existence of common objectives and ways of thinking among actors causes them to be seen as more reliable and less likely to act opportunistically, which can ultimately make it easier to access knowledge and information.

In these dimensions context, indicated Karahanna, Preston (2013) that for knowledge exchange and combination to occur and subsequently lead to knowledge integration, individuals must be afforded the opportunity to interact in order to share 
their knowledge, they must be motivated to engage in the interaction, and they must have the cognitive ability to combine or integrate the information or experience. Thus, these conditions correspond to the three dimensions of social capital which act as drivers of knowledge exchange and combination. Since (1) the structural dimension provides opportunities for interaction through network ties, (2) the cognitive dimension facilitates interaction, makes information held by others accessible, and aids in the assimilation of new knowledge through a common vocabulary and cognitive frames, and (3) the relational dimension provides the motivation to engage in exchange and combination for knowledge creation. In turn, knowledge exchange and combination allow for knowledge integration and thus the creation of new intellectual capital, defined as the knowledge and knowing capability of a social collectivity. In the same context, adds Bousrih (2013) that social capital can have three forms, firstly, obligations and expectations which depend on the trustworthiness of the social environment, secondly, the capacity of information to flow through social structure in order to provide a basis for action and thirdly, the presence of norms accompanied by effective sanctions.

Social capital can be considered as an asset of an individual, but it can also be viewed at the community or firm level. Social capital is often divided into two forms or types: structural and cognitive social capital, where cognitive social capital encompasses norms and trust, while structural social capital includes social networks both formal and informal. Norms can be viewed as a social contract or unwritten rules. While Trust can be described as confidence in the reliability of others, where people act for the benefit of others and expect to get help in return when it is needed. Where, Informal networks are formed by the interpersonal relationships between friends, relatives, colleagues, neighbors, etc. In contrast to formal networks, where the boundaries can be drawn on the basis of membership in these organizations. But both formal and informal networks provide support and communication channels for information exchange (Kaasa, 2007). There are two main approaches to explain the concept of social capital: one considers social capital as an individual attribute and another argues that social capital or the social network is more an attribute of community itself. At an individual level, social capital is presented as an individual resource where rational and well informed people invest in social capital within a utility maximization problem. Moreover, a clean social environment where people meet freely and frequently is an ideal ground for the adoption and diffusion of good norms and trust. A generalized trust in society reduces uncertainty and the average transaction costs just like other inputs reducing transactions or production costs. At an aggregate level, generalized trust-based relations may have a positive impact on the process of development and economic growth in particular. It may also be a factor that accounts for the gap in growth performances between regions even in developed countries and the underdevelopment of urban and rural areas in poor countries. individual in societies with high trust and norms of civic cooperation spends less time in protecting himself against exploitation in economic transactions and for diverting resources in order to protect them (Bousrih, 2013). Social capital is the network of social associations that influence individual actions and thereby affect economic expansion.... Organizational social capital is resources that show the character of social relation within the organization (Ali et al., 2013).

Social capital at the organizational level provides leverage that supports, improves, and at times, changes the infrastructure of the organization. Social capital assists organizations in their ability to assimilate to the environmental changes that occur in an organization and accommodate these changes (Chazon, 2009).

Adler and Kwon (2002) compares between social capital and other forms of capital. First, like all other forms of capital, social capital is a long-lived asset into which other resources can be invested, with the expectation of a future (albeit uncertain) flow of benefits. Through investment in building their network of external relations, both individual and collective actors can augment their social capital and thereby gain benefits in the form of superior access to information, power, and solidarity. And by investing in the development of their internal relations, collective actors can strengthen their collective identity and augment their capacity for collective action. Second, like other forms of capital, social capital is both appropriable and convertible. Social capital is appropriable in the sense that an actor's network of, say, where friendship ties can be used for other purposes, such as information gathering or advice. And social capital can be converted to other kinds of capital: the advantages conferred by one's position in a social network can be converted to economic or other advantage. Third, like other forms of capital, social capital can either be a substitute for or can complement other resources. As a substitute, actors can sometimes compensate for a lack of financial or human capital by superior connections. Also, social capital complements other forms of capital, for example, social capital can improve the efficiency of economic capital by reducing transaction costs. Fourth, social capital needs maintenance. Where social bonds have to be periodically renewed and reconfirmed or else they lose efficacy. Social capital does not have a predictable rate of depreciation-for two reasons: while it may depreciate with non-use (and with abuse), it does not depreciate with use. And, while social capital sometimes is rendered obsolete by contextual changes, the rate at which this happens is typically unpredictable so that even conservative accounting principles cannot estimate a meaningful depreciation rate. Fifth, unlike many other forms of capital, some forms of social capital are collective goods in that they are not the private property of those who benefit from them. Sixth, social capital is unlike all other forms of capital in being located not in the actors but in their relations with other actors, while it takes mutual commitment 
and cooperation from both parties to build social capital, a defection by only one party will destroy it. Finally, social capital investments in its development do not seem amenable to quantified measurement, even in principle indicated Edwards (2004) that a characteristic of all types of capital (Produced economic capital, Natural capital, Human capital and Social capital) is that stocks depreciate over time and increase through investment and (in some cases) natural regeneration. For all of these resources, changes in flows take time to affect underlying stock. Another common feature of all types of capital is that they accumulate and are restored slowly, while they can be dissipated quickly if not used sustainably.

Also, Biddle et al. (2009) see that social capital is seen as being a resource which draws on and feeds into other types of resources (natural, produced economic and human capital).

\section{Sources of Social Capital}

General, based on the above and depending on many of the studies can be pointed out that sources of social capital are:

- Networks: are patterns of relationships, and also patterns of the resources brought to the relationship by participants. Potential resources brought by participants to a relationship are their personal skills and abilities, their economic resources, resources associated with their jobs, status, and with the other groups to which they are connected, and, by extension, the networks and resources of their families, friends and colleagues. Thus, social capital exists in the relationships between participants. Features of network structure influence the range and quality of resources accessible to an individual. The size of a network often reflects the amount of investment made in relationships and provision of support, and increases the capacity of an individual to draw on these resources. The frequency of interaction relates to the accessibility of these resources. (Edwards, 2004). Social networks are regarded a kind of prerequisite to build up social capital. Engagement in networks is a necessary condition for the emergence of social capital (Schaik, 2002). Social networks enable the mobilization of social contacts from which an individual can benefit (Putnam, 2000). Can be seen that networks are a source of social capital through the following comments: where Baker (1990) see social capital is a resource that actors derive from specific social structures. And Burt (1997) think the structural hole is an opportunity to individual the flow of information between people and control the form of projects that bring together people form opposite sides of the hole. In other hand, indicated $\mathrm{Fu}$ (2004) that a closed social network -the existence of strongly interconnected and mutually reinforcing relations between different actorsmaintains the existence of effective norms and the trustworthiness of others, hence strengthening social capital.
By contrast, a more open structure is less likely to allow individuals within it to detect a violation of norms, which may result in less trust among network members and here by weaken social capital. Also, Nahapiet and Ghoshal defined social capital as the sum of the actual and potential resources embedded within, available through, and derived from the network of relationships possessed by an individual or social unit. Social capital thus comprises both the network and the assets that may be mobilized through that network. Putnam (2000) see that social capital refers to connections among individuals - social networks and the norms of reciprocity and trustworthiness that arises from them-. Portes (1998) see that to possess social capital, a person must be related to others, and it is those others, not himself, who are the actual source of his or her advantage.

In networks where people do not know everyone, or where the overlap of participants between groups is less, or where a wider variety of people is able to gain access to the group. Higher quality information or influence may be available from relationships with people of similar status in different institutions or fields, and with people of higher status with greater access to influence (Edwards, 2004).

- Norms: Social norms are shared understandings, informal rules and conventions that prescribe, proscribe or modulate certain behaviors in various circumstances. Generalized social norms can include honesty, law abidingness, the work ethic, respect for elders, tolerance and acceptance of diversity, and helping people in need (Commonwealth of Australia, 2003). Social capital is based on shared norms, mainly generalized reciprocity. Generalized reciprocity is based on the assumption that today's good turns will be repaid sometime in the future ( $\mathrm{Fu}, 2004)$. Thus, Generalized reciprocity thus involves a degree of uncertainty, risk, and vulnerability (Schaik, 2002).

An approach closer to the under socialized view of human nature in modern economics sees social capital as primarily the accumulation of obligations from others according to the norm of reciprocity. The internalized norms that make particular behaviors possible are then appropriable by others as a resource of social capital. That has two consequences. First, the donor's returns may come not directly from the recipient but from the collectivity as a whole in the form of status, honor, or approval. Second, the collectivity itself acts as guarantor that whatever debts are incurred will be repaid (Portes, 1998). In the same context. Indicated Ariani (2012) that Social capital is based on social exchange theory: one individual gives profit to others voluntarily in a reciprocal pattern. according to Edwards (2004) Reciprocity is any relationship between two parties or things where there is a mutual action, giving and taking. Social Capital Framework, is not seen just 
as an exact exchange at a point of time. An action may be in response to one that took place much earlier, or in expectation of a response at a time of need in future. The return may be different in nature.

The working definition of social capital refers to the networks, norms and understandings that facilitate cooperative activities within and among groups of individuals (Helliwell, 2001). Also, indicated Edwards (2004) that Network qualities describes the norms and values that may exist within networks, and serve to enhance the functioning of networks. These include but are not limited to, trust, reciprocity, cooperation, and acceptance of diversity. These norms and values are essential to healthy functioning of networks because they encourage people to act cooperatively, and effectively provide rules and sanctions to govern people's behavior. More specifically, norms such as trust and reciprocity are important because they may help reduce transaction costs relating to negotiation and enforcement, and encourage the sharing of knowledge and ideas.

- Shared belief: cognitive dimension serves as a resource and provides shared representations, interpretation, and systems of meaning among parties (Fu, 2004). In the same context, Portes (1998) indicated to by being thrown together in a common situation, workers learn to identify with each other and support each other's initiatives.

Also, Adler and Kwon (2002) classified sources of social capital in opportunity - motivation - ability framework. Opportunity: An actor's network of social ties creates opportunities for social capital transactions. External ties to others give actors the opportunity to leverage their contacts' resources. For collective actors, internal ties create the opportunity to act together.

Motivation: why the recipients in transactions mediated by social capital should desire its benefits, is what motivates donors to help recipients in the absence of immediate or certain returns. That motivations constitute a direct source of social capital, where motivations are based on deeply internalized norms, engendered through socialization in childhood or through experience later in life by the experience of a shared destiny with others. Also, a motivation is based on obligations created in the process of dyadic social exchange where obligations are enforced on both parties by the broader community. In same context, add Edwards (2004) that The giving may be an investment in a process where the return to the giver is a generalized improvement in which others as well as the giver participate. The return may be the sense of satisfaction in enabling things to be done that the giver wishes to see done. Ability: is the competencies and resources at the nodes of the network, it only includes the resources that actors could potentially mobilize via their social relations.
Thus, opportunity-motivation-ability framework suggests that all three sources must be present for social capital to be activated. A prospective donor without network ties to the recipients, without the motivation to contribute, or without the requisite ability would not be a source of social capital. A lack of any of the three factors will undermine social capital generation.

\section{Conclusions}

Through the above, we can conclude the following:

- Social interaction between individuals or groups can be negative (i.e. Negative feelings are characteristic of relations between the parties) or a positive push toward achieving the benefits of individual and collective, which generates a social capital. Thus, positive social interaction + individual and collective goals $=$ social capital. Social capital generates and evolves in organization according to regulations, laws, and environment of organization, that should be formulated to generate a positive human interaction contributes to achievement of individual and organizational goals.

- Since social capital is formed through the relationships between individuals, groups or organizations. That means, its form and its nature is follow to individual or collective characteristics to those actors. Thus, the transfer it or imitate it is not possible. For example, trust among some employees in an organization cannot be copied to another organization. Thus, the competitive advantage derived through social capital is a special weapon of organization in their struggle to survive and continuity. In further, can be a social capital is a main explainer for the success of the human group (whether an organization or society). We can say that social capital is identity of a human group, and image of its development track.

- Relations between individuals are internal ties to their group, relations with their group and other groups are internal ties to their community, and relations between their community and other communities are internal ties to a broader grouping. Thus, the concept of social capital is inherent to all levels of social interaction, which means that social capital should be considered when doing analytical studies or developmental applications of the reality modern human. In further, it is noted that dealing with contemporary societies is not limited to formal structures only, but also extends to the characteristics of social interactions. It is a feature of contemporary international relations.

- Generation and development of social capital of organization is subject to conditions do not fall whole under control of the organization. The organization can put appropriate organizational structures and Allocation of work etc, but it does not control on quality of norms and beliefs that are attended by employees from their environments and that 
reflect their upbringing and their experiences. Thus, that develop social capital who contributes to achieving individual and organizational and community goals, Requires coordination between business organizations and local communities and society. Which reflects the gradient and accumulated and inclusiveness that characterizes process of building social capital. Which means that social capital is more realistic indicator of the development of a group or community or society.

- Appropriate Social capital means that the individual is ready to provide efforts for achieve the goals of organization because this means achievement of his goals. Thus, concept of social capital is an approach to a concepts as empowerment, organizational citizenship and other that can be subjects of an future studies.

The social capital concept has thus been widely used to explain the importance of social factors to increase level of performance and achieving goals of the organization. The basic idea of social capital is that it improves communication between individuals, generates cooperation that can be a benefit for the individuals and also for the organization in general. that the relationships between or within a group at different levels in organization creates social environment that will impact positively on performance development. Moreover, a clean social environment where people meet freely and frequently is an ideal ground for the adoption and diffusion of good norms, as well as trust. In this respect, enhance social advantages of the organization is also a matter of knowing how to maintain good strategy and to sustain high level of performance over time.

\section{References}

Adler, P. S., Kwon, S. (2002) Social Capital: Prospects for a New Concept". Academy of Management Review. 27 (1). pp. 17-40. DOI: $10.2307 / 4134367$

Ali, M., Hussain, A., Azim, A. (2013) Organizational Investment in Social Capital (OISC) and Employee Job Performance: Moderation by Employee Job Engagement. International Review of Management and Business Research. 2 (1). pp. 250-257. Available from: http://irmbrjournal.com/papers/1367573449.pdf

Anheier, H. K., Gerhards J., Romo, F. P. (1995) Forms of Capital and Social Structure in Cultural Fields: Examining Bourdieu's Social Topography. American Journal of Sociology. 100 (4). pp. 859- 903. DOI: $10.1086 / 230603$

Ariani, D. W. (2012) The Relationship Between Social Capital, Organizational Citizenship Behaviors, and Individual Performance: An Empirical Study from Banking Industry in Indonesia. Journal of Management Research. 4 (2). pp. 226-241. DOI: 10.5296/jmr.v4i2.1483

Aziri, B. (2011) Job Satisfaction: a Literature Review. Management Research and Practice. 3 (4). pp. 77-86. Available from: http://mrp.ase.ro/no34/f7.pdf

Baker, W. (1990) Market Networks and Corporate Behavior. American Journal of Sociology. 96. pp. 589-625. DOI: 10.1086/229573

Biddle, N., Davis, E., Myers, J., Dodhy, R. S. (2009) Exploring Measures of Low Social Capital. Australian Bureau of Statistics.
Bourdieu, P. (1986) The Forms of Capital. In: Richardson, J. G. (ed.) Handbook of Theory and Research for The Sociology of Education. New York, Greenwood.

Bousrih, L. (2013) Social Capital, Human Capital and Sustainable Economic Development. Poznan University of Economics Reviews. 13 (3). pp. $42-54$.

Burt, R. S. (1997) The Contingent Value of Social Capital. Administrative Science Quarterly. 42 (2). pp. 339-365. DOI: 10.2307/2393923

Burt, R. S. (1992) Structural Holes: The Social structure of Competition. Harvard University Press.

Chazon, T. L. (2009) Social Capital: Relationship Between Social Capital and Teacher Job Satisfaction Within a Learning Organization. GardnerWebb University.

Coleman, J. S. (1988) Social Capital in The Creation of Human Capital. American Journal of Sociology. 94. pp. 95-120.

Edwards, R. W. (2004) Measuring Social Capital. Australian Bureau of Statistics. Available from: http://www.ausstats.abs.gov.au/ausstats/free.nsf/Lookup/13C0688F6B98DD45CA256E360077D526/\$ File/13780_2004.pdf

Flap, H., Volker, B. (2001) Goal Specific Social Capital and Job Satisfaction Effects of Different Types of Networks on Instrumental and Social Aspects of Work. Social Networks. 23 (4). pp. 297-320. DOI: 10.1016/s0378-8733(01)00044-2

Fu, Q, (2004) Trust, Social Capital, and Organizational Effectiveness. The Faculty of the Virginia Polytechnic Institute and State University. Available from: http://www.ipg.vt.edu/papers/qhfumajorpper.pdf

Helliwell, J. F. (2001) Social Capital, the Economy and Well- Being. The Review of Economic Performance and Social Progress. pp. 43-60.

Kaasa, A. (2007) Effects of Different Dimensions of Social Capital on Innovation: Evidence From Europe at The Regional Level. University of Tartu, no.69. Available from: http://ftp.repec.org/opt/ReDIF/RePEc/mtk/ febpdf/fe bawb51.pdf

Karahanna, E., Preston, D. (2013) The Effect of Social Capital of The Relationship Between The CIO and Top Management Team on Firm Performance. Journal of Management Information Systems. 30 (1). pp. 15-55. DOI: $10.2753 / \mathrm{mis} 0742-1222300101$

Leana, C. R., Van Buren, H. J. (1999) Organizational Social Capital and Employment Practices. Academy of Management Review. 24 (3). pp. 538-555. DOI: $10.2307 / 259141$

Lin, N. (1999) Building a Network Theory of Docial Capital. CONNECTIONS. 22 (1). pp. 28-51. Available from: http://www.insna.org/PDF/ Keynote/1999.pdf

Nahapiet, J., Ghoshal, S. (1998) Social Capital, Intellectual Capital, and The Organizational Advantage. Academy of Management Review. 23 (2). p. 242-266. DOI: 10.1016/b978-0-7506-7222-1.50009-x

Narayan, D., Cassidy, M. F. (2001) A Dimensional Approach to Measuring Social Capital: Sevelopment and Validation of a Social Capital Inventory. Current Sociology. 49 (2). pp. 59-102. DOI: $10.1177 / 0011392101049002006$

Oliveira, J. F. (2013) The Influence of The Social Capital on Business Performance: an Analysis in The Context of Horizontal Business Networks. RAM, REV. ADM. MACKENZIE. 14 (3). pp. 209-235. DOI: $10.1590 / \mathrm{s} 1678-69712013000300009$

Portes, A. (1998) Social Capital: Its Origins and Applications in Modern Sociology. Annual Review of Sociology. 24. p.1-24. DOI: 10.1146/annurev.soc.24.1.1

Portes, A., Sensenbrenner, J. (1993) Embeddedness and Immigration: Notes on The Social Determinants of Economic Action. American Journal of Sociology. 98. pp. 1320-1350. DOI: 10.1086/230191 
Putnam, R. (2000) Bowling Alone: The Collapse and Revival of American Community. New York: Simon and Schuster

Putnam, R .D. (1995) Bowling Alone: America's Declining Social Capital. Journal of Democracy. 6 (1). pp. 65-78. Available from: http://archive. realtor.org/sites/default/files/Bowling Alone.pdf

Rostami, M., Ghazvini, M. H., Farmani, M., Saraei, A. (2013) Relation of Organizational Social Capital With Job Satisfaction and Job Stress: an Empirical Investigation. Journal of Basic and Applied Scientific Research. 3 (3). pp. 578-583. Available from: http://www.textroad. com/pdf/JBASR/J.\%20Basic.\%20Appl.\%20Sci.\%20Res.,\%203(3)578583,\%202013.pdf

Savari, M., Eslami, M., Monavarifard, F. (2013) The Impact of Social Capital on Agricultural Employees' Job Satisfaction, City of Divandarreh. International Research Journal of Applied and Basic Sciences. 4 (2). pp. 291-295. Available from: http://www.irjabs.com/files_site/ paperlist/r_669_130304194523.pdf

Schaik, T. (2002) Social Capital in The European Values Study Surveys. paper prepared for the OECD-ONS International Conference on Social Capital Measurement. London. Available from: http://www.oecd.org/edu/innovation- education/2381883.pdf
Tian, J., Haleblian, J., Rajagopalan, N. (2011) The effects of board human and social capital on investor reactions to new CEO selection. Strategic Management Journal. 32. pp. 73-747. DOI: 10.1002/smj.909

Tomlinson, P. R. (2011) Industry Institutions, Social Capital, and Firm Participation in Industrial Development. Industrial and Corporate Change. 21 (1). pp. 1-29. DOI: 10.1093/icc/dtr028

Zappa, P., Zavarrone, E. (2009) Social Interaction and Job Satisfaction in Non Profit Organizations. Venice, The HEIRs Conference on Happiness and Relational Goods. Available from: http://www.happinesseconomics.net/ ocs/index.php/heirs/relationalgoods/paper/viewFile/114/71OTHER:

Commonwealth of Australia (2003) Productivity Commission. Social Capital: Reviewing the Concept and its Policy Implications. Canberra, Research Paper. Available from: http://www.pc.gov.au/244/socialcapital.pdfdata/ assets/pdf_file/0018/8 